\title{
EFFECT OF ENTRANCE ON SEICHE MOTION IN OCEAN PORTS
}

\author{
Nikhilesh Roy \\ Assistant Professor, C1vil Engineering Department \\ Indian Institute of Technology, Kharagpur, India.
}

\section{ABSTRAOT}

The seiche motion induced in a partially open harbour is uniquely determined by the standing wave pattern formed in the outside ocean. The variable location and size of the coupling makes the problem essentially three-dimensional. Existing potential theory has been extended, for the case of a simple rectangular port, to simulate ocean conditions by approximating the open ocean by anothe $r$ rectangular basin of large size. The theoretical problem then reduces to solving the Neuman problem for the two-dimensional Helmholtz equation $\nabla^{2} F+K^{2} F=0$ for a polygonal contour. The finite dimensional approximation of an infinite domain is, however, unsatisfactory at least from the analytical point of view. This difficulty has been removed, in this paper, by using elliptic-cylindrical co-ordinates for the semi-infinite domain in which the perturbation potential has been expanded in terms periodic Mathieu functions. These theoretical developnents have been verifled by a serles of numerical calculations and experimental studies,

\section{INIRODUC'PION}

The phenomenon of lone period standing wave is variously termed as surge, $s \in 1$ che motion, or simply selche. When resonance occurs in the induced motion in the port, the amplitude of motion is magnified, sometimes greatly, and although the heleht of surge may be smaller than that of storm waves, the horlzontal water motion is usually large. Since a ship is small compared to the wave length of a seiche motion, it may be expected to move in space with water motion unless rigldiy restrained. Although this type of wave motion and consequent damages to ship were first observed in the Paciflc coast of the U.S.A. (1), recent reports $(2,3)$ ind1cate that such motion exists in many coastal regions of the world and has been a source of serlous concern to harbour authorities at these places.

Because of the extremely small steepness of the selche waves, a standing wave pattern exists offshore of any coast line that recelves such waves. If this coast ine is now broken to accomodate an entrance to a port, a part of the incldent wave is transmitted inslde and suffers multiple reflections at the harbour boundaries. Depending on the boundery geometry, a forced oscillation results which, if losses are neglected, is in phase with the outside motion. 


\section{COASTAL ENGINEERING}

The free surface pattern is dominated by the nearest free oscillation mode of the harbour assumed closed on all sides. The two-dimensional picture of the open sea also undergoes a local deformation around the harbour mouth which dies out with increasing distance at a rate depending upon the ratio of the entrance width to the wave length. The oscillations inside and outside of the port should, therefore, be cons1dered parts of the same motion. Mathematically, this means that the potential of motion should be that of standing wave both insiae and outside of the port, the analytic continuity of the two functions being maintained through the harbour mouth.

The theoretical treatment when the open sea is approx1mated by a finite basin is relatively simple and was developed by Apte'(4) and recently extended by Ippen and Ralchlen( In both cases an experimental model was selected to represent ocean conditions near the harbour mouth as each investigator thought appropriate. This model, which in the case of Raichlen was more representative of the prototype situation, was then analysed theoretically under certain restrictive conditions.

On the other hand, until Miles and Munk(6) published their work, there was no analytical solution avaliable for the open sea case. Their approach was, however, somewhat different as they assumed the harbour to osciliate freely and, tue to the presence of the entrance opening, radiate ene rey toward the open sea. This raliated enerey is radially diffused in the open expanse and lost to the harbour itself thus limiting the maximum amplification of the harbour system at resonance. As a result, the potential of motion Inside the port was that of standing wave and that outside, of a standing wave and progressive wave. However, in computing the resonant wave number, only the real part of the open sea potential was considered.

The present studies were undertaken when neither the work of Ralchlen nor that of Miles and Munk were published. Even then, there are material differences in the work described here and those referred above. Figures 1 and 2 show the relative position of the port, the outer sea and a channel of variable length that connects the two. In fie.1, the outer sea has been assumed finite while flg.2 shows this basin to be infinite in extent. The arrangement shown in these fipures are more general than those considered previously because, in any physical situation, the harbour does not begin immedlately shoreward of the sea. In fact, ports with 'narrow' approach channels of finite length are not rame in nature. 


\section{EFFECT OF ENTRANCE ON SEICHE MOTION IN OCEAN PORTS}

In the present studies only waves with crests parallel to the coast line have been considered. The outer boundary of the finite open sea is constituted by a virtual wall at an antinodal line that is sufficiently away from the harbour mouth to be appreclably di storted by the presence of the ojening. For the semi-infinite open sea, it is necessary to consider, in addition to the two-dimensional standing wave potential, a perturbation potential which possesses a finite gradient at the harbour mouth, a zero gradient at the rest of the coast line and disappears at laree ilstances from the mouth. Such a solution is avaliable if we use ellipticcylindrical co-ordinates and expand the perturbation potential of the open sea in terms of periodic angular and radial Mathieu functions, the angular functions forming an ortrogonal set. It may be remarked here that the Hankel function expansion proposed by Miles is convenient only as long as the harbour entrance is 'narrow'. Besides, the varlational princlple used in their analysis can not predict the complete response curve and the form of the proposed entrance velocity distribution function leads to an arbitrary entrance velocity and consequently an arbitrary amplitude of motion at resonance although, the power amplification is finite.

Perhaps, this brief review will be incomplete without a reference to the valuable work done by $B$ iesel and Le Me'haute' $(7,8)$ in this field. But, their approach, was, essentially, two-dimensional, the harbour entrance beling treated as a localised obstruction in the passage of progressive waves. It is apparent that such an approach can take care of the width of the opening but not its location in the seward side of the port which, as will be shown later, plays an important role in those oscillations of the harbour that are primarily transversal. Unfortunately, transversal

oscillations have not recelved much attention so far although, such motions are not at all unusual in harbours.

THEORETICAL STUDIES

FHE' MODEL

In the figures 1 and 2 the domains of the port, canal, and the sea are denoted $D_{p}, D_{c}$ and $D_{s}$ respectively, the domain $D_{S}$ being placed symmetrically with respect to the domain $D_{p}$. The basins are of constant depth $h$ and the boundary walls are assumed vertical. The axes of reference are Oxyz, the Oxy plane coinciding with the mean water level in the basins, and the axis $O z$ is directed vertically upwards so that $z=-h$ denotes the bottom of the basins. It may be noted that the oide GFKJ represents the botally reflecting coast line which extends, in the case of semi-infinite outer domain, to infinity in the positive \& negative $x$-direction. 


\section{COASTAL ENGINEERING}

The desired standing wave pattern in the closed domain $D_{s}$ is produced by a wave train incident at the other end of the long, narrow wave canal shown at extreme right of figure 1 The analysis presented in the following papes can be utilised to show that this arrangement produces neglieible disturbance

\section{BASIC THEORY}

The flow is assumed irrotational. As the wave steepness is very small, the exact linear surface wave theory can be used to solve this three dimensional-problem.

The velocity potential satisfying the Laplace, free surface and the bottom surface conditions can be written, assuming simple harmonic oscillation, as :

$$
\phi_{P_{0} t}=-\frac{g T}{2 \pi} \cdot \cos \frac{2 \pi t}{T} \cdot \frac{\operatorname{Cosh} K(z+h)}{\operatorname{Cosh} K h} F(x, y) \ldots
$$

Where $T$ is the period of the generating wave, and $F(x, y)$ satisfies the differential equation :

$$
\nabla^{2} \mathrm{~F}+\mathrm{K}^{2} \mathrm{~F}=0
$$

$K$ is related to the period by the equation

$$
\left(\frac{2 \pi}{T}\right)^{2}=8 \mathrm{~K} \quad \tanh \pi \mathrm{h} \quad \ldots
$$

In addition to (2), F satisfies the condition

$$
\frac{\partial F}{\partial n}=0 \quad \ldots
$$

alone the vertical walls of the port, where $n$ is the direction of the outward drawn normal to the boundary of the basins. Along the two parts of the boundary occupied by the left and right and of the communicating canal we can write

$$
\begin{aligned}
\text { (1) } \frac{\partial F_{p}}{\partial n} & =-\frac{\partial F_{0}}{\partial n} \text { for } y=0 \\
\text { i.e. } \frac{\partial F_{p}}{\partial y} & =\frac{F_{c}}{\partial y}=V s(x) \text { for } y=0 \ldots \\
\text { (11) } \frac{\partial F_{c}}{\partial n} & =-\frac{\partial F_{s}}{\partial n}, \text { for } y=-L \\
\text { i.e. } \frac{\partial F_{c}}{\partial y} & =\frac{\partial F_{s}}{\partial y}=G^{s}(x), \text { for } y=-L, \ldots
\end{aligned}
$$


EFFECT OF ENTRANCE ON SEICHE MOTION IN OCEAN PORTS

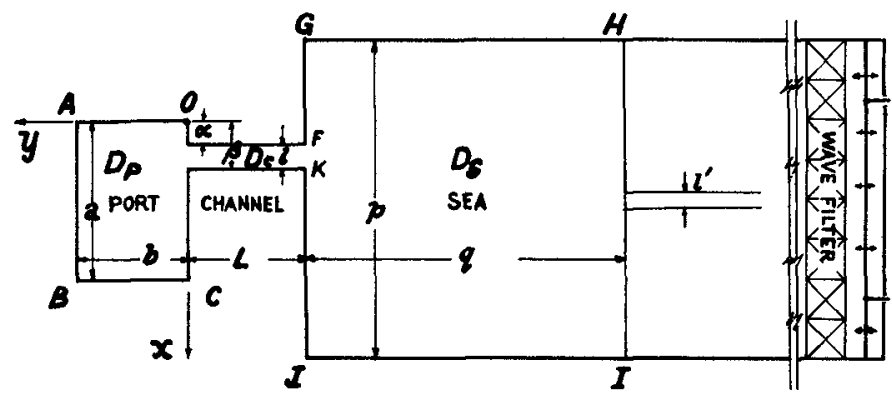

Fig. 1. Rectangular harbour and approach channel connected to a finite wave basin.

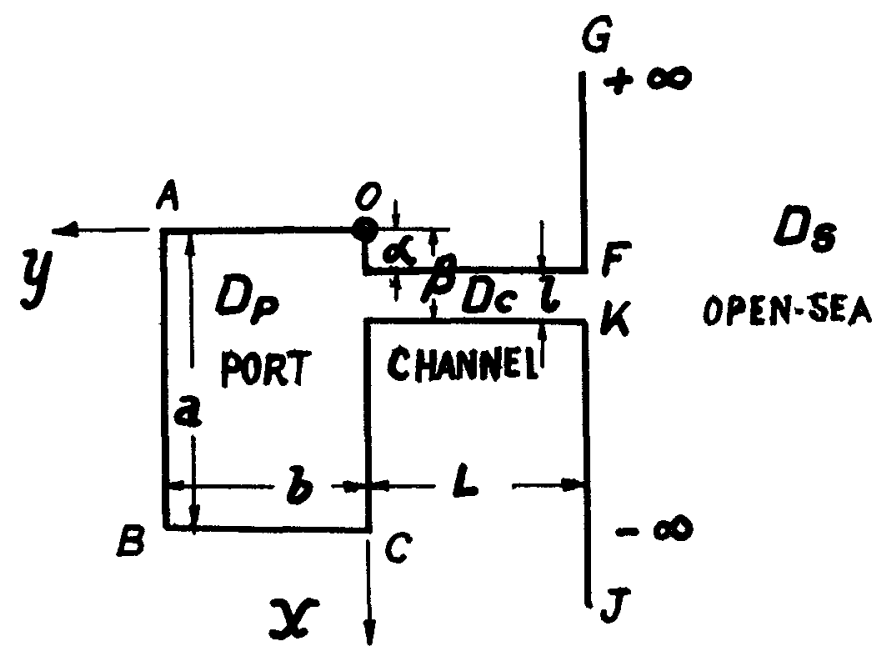

Fig. 2. Rectangular harbour and approach ohannel connected to an open sea.

\section{DE - OPEN SEA DOMAIN}

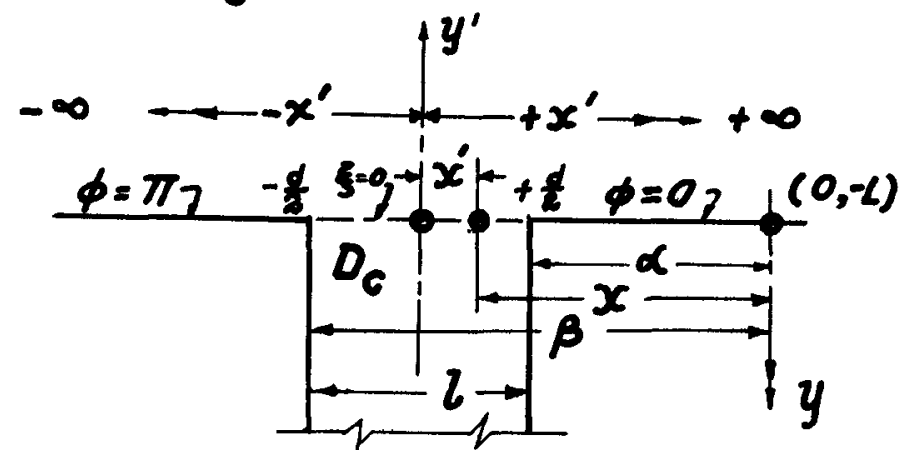

Fig. 3. Co-ordinate system used in the open sea analysis. 


\section{COASTAL ENGINEERING}

where the subscripts of $F$ are the domain subscripts, The two auxiliary functions $\nabla^{S}(x)$ and $G^{s}(x)$ are defined by the following fourier series representation

$$
\begin{aligned}
& V^{s}(x)=\sum_{m=0}^{\infty} U_{m} \cos \frac{m \pi x}{a}=\sum_{k=0}^{\infty} f_{k} \cos \frac{k \pi(x-\alpha)}{\frac{1}{0},}, \begin{array}{c}
\alpha \leqslant x<\beta \\
\beta<x<\theta
\end{array}
\end{aligned}
$$

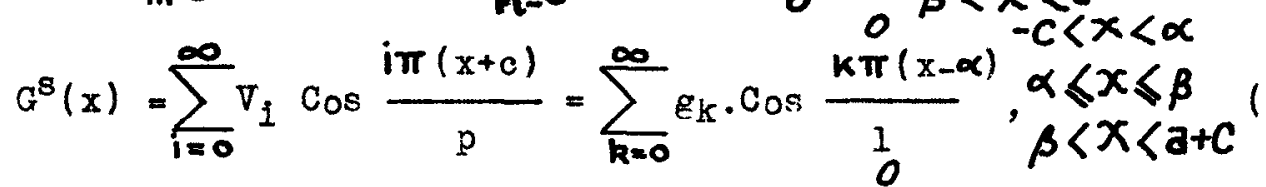

Again the equality of water level at the common sections gives us;

$$
\begin{aligned}
F_{p} & =F_{c} \text { for } y=0, \\
\text { and } \quad F_{c} & =F_{s} \text { for } y=-I,
\end{aligned}
$$

\section{ANALYTICAL DEVELOPMENT}

The Helmholtz equation, eqn (2), is solved for the various basins by expanding the $F$ functions in terms of the eigen functions of the se separate basins assumed closed. Only those frequencies of excitation are considered here which givenresonance" in the domains $D_{p}$ and $D_{s}$ individually. This gives

$$
K^{2}=\pi^{2}\left(\frac{m_{0}^{2}}{a^{2}}+\frac{n_{0}^{2}}{b^{2}}\right)=\pi^{2}\left(\frac{i_{0}^{2}}{p^{2}}+\frac{J_{0}^{2}}{q^{2}}\right)
$$

where $m_{0}, n_{0}$ and $1_{p}$, jo represents the number of nodal lines parallel to the corresponding sides of the two basins. However, the general development is valia for other frequencles as well.

We now write the $F$ functions for the various domains noting that these, when substituted in eqn.(1), give the corresponding velocity potentials

$$
\begin{aligned}
& \text { (1) Domain } D_{p} \\
& F_{p}(x, y)=\sum_{m=0}^{m<\frac{a k}{m}} U_{m} \cos \frac{m \pi x}{a} \cdot \frac{\cos \phi_{m}(y-b)}{\phi_{m} \sin \phi_{m} b}+ \\
& +R_{m o} \cos \frac{m_{0} \pi x}{a} \cdot \cos \frac{n_{0} \pi y}{b}-\sum_{m>a k / \pi}^{\infty} U_{m} \cos \frac{m \pi x}{a} \cdot \frac{\cosh \phi_{m}^{\prime}(y-b)}{\phi_{m}^{\prime} \sinh \phi_{m}^{\prime} b} \cdot(12)
\end{aligned}
$$




\section{EFFECT OF ENTRANCE ON SEICHE MOTION \\ IN OCEAN PORTS}

(11) Doma in $D_{c}$ :

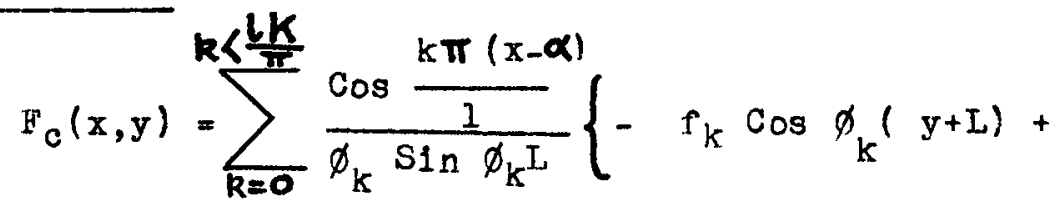

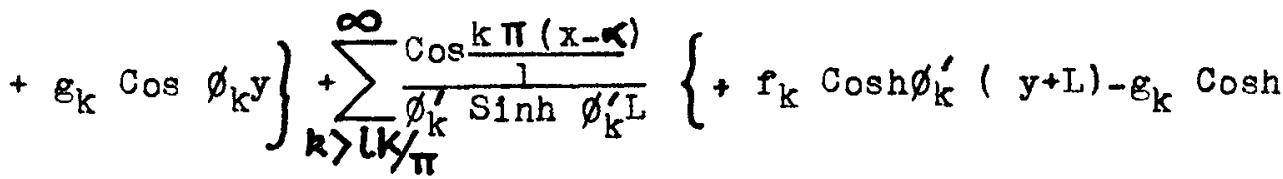

$$
\left.\phi_{\mathrm{k}}^{\prime} \mathrm{y}\right\}
$$

(iii) Domain $D_{s}$ :

$$
F_{s}(x, y)=-\sum_{i=0}^{i<\frac{k K}{\pi}} v_{1} \cos \frac{1 \pi(x+c)}{p} \cdot \frac{\operatorname{Cos} \phi_{1}(y+L+q)}{\phi_{1} \sin \phi_{1} q}+
$$

$$
\begin{aligned}
P_{10} \operatorname{Cos} \frac{1_{0} \pi(x+c)}{p} \operatorname{Cos} \frac{J_{0} \pi y}{q} & +\sum_{\substack{i>p K / \pi \\
1}}^{\infty} \operatorname{Cos} \frac{1 \pi(x+c)}{p} \\
& \frac{\operatorname{Cosh} \phi_{1}^{\prime}(y+L+q)}{\phi_{1}^{\prime} \sinh \phi_{1} q} \ldots
\end{aligned}
$$

Where

$$
\begin{aligned}
& \phi_{\mathrm{m}}=\left(\mathrm{K}^{2}-\frac{\mathrm{m}^{2} \pi^{2}}{a^{2}}\right)^{\frac{1}{2}} ; \phi_{\mathrm{m}}^{\prime}=\left(\frac{\mathrm{m}^{2} \pi^{2}}{a^{2}}-k^{2}\right)^{\frac{1}{2}} \\
& \phi_{\mathrm{k}}=\left(\mathrm{K}^{2}-\frac{\mathrm{k}^{2} \pi^{2}}{1^{2}}\right)^{\frac{1}{2}} ; \phi_{\mathrm{k}}^{\prime}=\left(\frac{\mathrm{k}^{2} \pi^{2}}{1^{2}}=\mathrm{K}^{2}\right)^{\frac{1}{2}} \\
& \phi_{\mathrm{i}}=\left(\mathrm{k}^{2}-\frac{1^{2} \pi^{2}}{\underline{0}^{2}}\right)^{\frac{1}{2}} ; \phi_{1}^{\prime}=\left(\frac{\mathrm{i}^{2} \pi^{2}}{\mathrm{p}^{2}}-\mathrm{k}^{2}\right)^{\frac{1}{2}}
\end{aligned}
$$

These expressions satisfy the partial derivative equations (5) and (6) with the help of first definitions of the auxiliary functions given in equations $(7)$ and $(8)$. 


\section{COASTAL ENGINEERING}

It may be noted that the various Fourier coefficients are yet unknown. The coefficients $f_{k}$ and $g_{k}$ are determined by applying the matching conditions prescribed in equations (9) and (10).

Analytic continuity of the velocity potential at the left end of the coupling canal $(\mathrm{y}=0)$ gives, then,

$$
\begin{aligned}
& \sum_{k=0}^{\infty} f_{k} A_{k} \cos \frac{k \pi(x-\alpha)}{1}-\sum_{k=0}^{\infty} \varepsilon_{k} B_{k} \cdot \cos \frac{k \pi(x-\alpha)}{1} \\
& =\sum_{m=0}^{\infty} U_{m} A_{m} \operatorname{Cos} \frac{m \pi x}{a}+R_{m o} \operatorname{Cos} \frac{m_{0} \pi x}{a} \ldots \ldots
\end{aligned}
$$

Where, the dashed summation sign indicates that the $m_{0}$ th term has been omitted in the infinite series in $m$, and

$$
\begin{aligned}
& A_{m}=\frac{\operatorname{Cot} \phi_{m} b}{\phi_{m}}, \quad m<\frac{a t}{\pi} \\
& =\frac{-\operatorname{coth} \phi_{m}^{\prime} b}{\phi_{m}^{\prime}}, m>\frac{a \pi}{\pi} \\
& A_{k}=-\frac{\operatorname{Cot} \phi_{k} \mathrm{I}}{\phi_{k}} ; B_{k}=-\frac{\operatorname{Cosec} \phi_{k}{ }^{L}}{1 \phi_{k}} ; k<\frac{1 \mathrm{~K}}{\pi} \\
& =+\frac{\operatorname{Coth} \phi_{k}^{\prime} L}{\phi_{k}^{\prime}} ;=+\frac{\operatorname{Cosech} \phi_{k}^{\prime} L}{\phi_{k}^{\prime}} ; k>\frac{1 K}{\pi}
\end{aligned}
$$

Both, the series in ejuation (18) are uniformly and absolutely convergent in the interval $\alpha \leqslant x \leqslant \beta$. Hence, we can multiply both sides of the equation by $\cos \frac{r \pi(x-\alpha)}{1}, r=0,1,2, \ldots, \infty$ and integrate, term by term, within that interval to obtain;

$$
\begin{gathered}
\mathrm{f}_{r} \mathrm{~N}_{r} A_{r}-\mathrm{B}_{r} \mathrm{~N}_{r} B_{r}=\sum_{m=0}^{\infty} U_{m} A_{m} M_{m r}+R_{m o} M_{m o r} \\
r=0,1,2, \ldots, \infty
\end{gathered}
$$


EFFECT OF ENTRANCE ON SEICHE MOTION IN OCEAN PORTS

Where, $N_{0}=1$ and $N_{r}=\frac{1}{2}$ for $r$

(18)

$$
\text { and } M_{m r}=\int_{\alpha}^{\beta} \cos \frac{m \pi x^{2}}{a} \cdot \cos \frac{r \pi(x-\alpha)}{1} \cdot d x
$$

Similarly, the analytic continuity at the right end of the canal $(y=-I)$ gives,

$$
\begin{aligned}
& \sum_{k=0}^{\infty} f_{k} B_{k} \cos \frac{k \pi(x-\alpha)}{1}-\sum_{k=0}^{\infty} g_{k} A K \cos \frac{k \pi(x-\alpha)}{1} \\
= & \sum_{i=0}^{\infty} V_{i} A_{1} \cos \frac{1 \pi(x+c)}{p}+P_{10} \cos \frac{1_{0} \pi(x+c)}{p} \ldots(19)
\end{aligned}
$$

Where,

$$
\begin{aligned}
A_{1} & =-\frac{\operatorname{Cot} \phi_{1}^{b}}{\not}, 1<\frac{p K}{\pi} \\
& \left.=\frac{\operatorname{Coth} \phi_{1}^{\prime} b}{\phi_{1}^{\prime}}, 1\right\rangle \frac{p K}{\pi}
\end{aligned}
$$

and the dashed summation sign indicates again, that the doth term has been omitted in the infinite series in 1.

Proceeding as before, we get :

$$
\begin{aligned}
f_{r} N_{r} B_{r}-E_{r} N_{r} A_{r} & =\sum_{i=0}^{\infty} V_{1} A_{1} M_{1 r}+P_{10} N_{10} r \\
r & =0,1,2,3, \ldots \ldots \infty
\end{aligned}
$$

(20)

where $N_{0}=1$ and $N_{r}=1 / 2$ for $r \geqslant 1$

Replacing $U_{m}$ and $V_{i}$ in terms of $f_{k}$ and $\varepsilon_{k}$, respectively from equns ( 7$)$ and $(8)$, we can rewrite equations (17) and (20) as below :

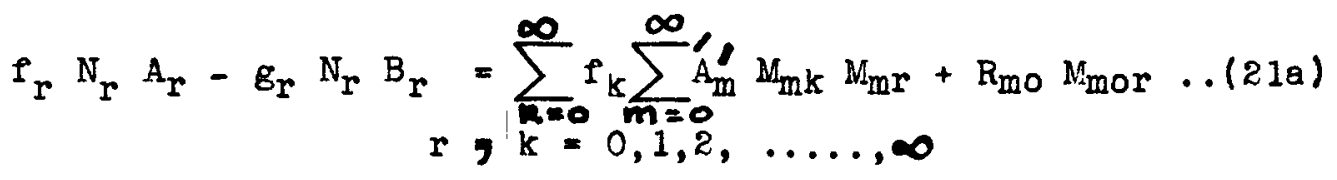

and

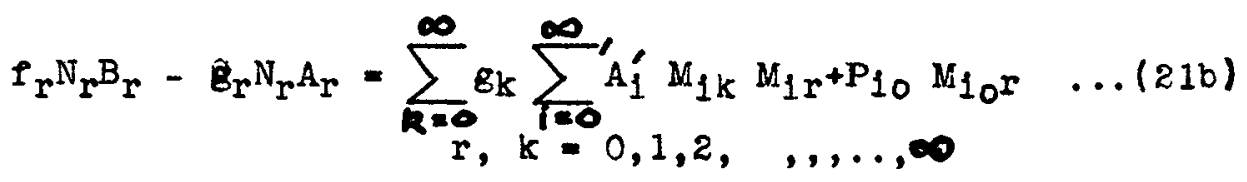

101 


\section{COASTAL ENGINEERING}

Where,

$$
\begin{aligned}
A_{m}^{\prime} & =\frac{1}{a} A_{m}, \text { for } m=0 ; A_{1}^{\prime}=\frac{1}{p} A_{1}, \text { for } 1=0 \\
& =\frac{2}{a} A_{m} \text { for } m \geqslant 1 ;=\frac{2}{p} A_{1}, \text { for } i \geqslant 1
\end{aligned}
$$

$$
\text { and } \begin{aligned}
N_{m k} & =\int_{\alpha}^{\beta} \cos \frac{m \pi x}{a} \cdot \cos \frac{k \pi(x-\alpha)}{1} \cdot d x \\
N_{i} k & =\int_{\alpha}^{\beta} \cos \frac{i \pi(x+c)}{p} \cdot \cos \frac{k \pi(x-\alpha)}{1} \cdot d x
\end{aligned}
$$

Similarly, $M_{m r}$ and $M_{1 r}$.

Writing equations (21) in matrix form

$$
\begin{gathered}
{\left[D_{r k}\right]+\left[\Lambda_{r k}\right]\left(g_{k}\right)+P_{10}\left(N 1_{0} r\right)=\left[\lambda_{r k}\right]\left(f_{k}\right)} \\
{\left[B_{r k}\right]-\left[\Lambda_{r k}\right]\left(f_{k}\right)+R m_{0}\left(N m_{0} r\right)=-\left[\lambda_{r k}\right](g k)} \\
k, r=0,1,2, \ldots \ldots+\infty
\end{gathered}
$$

Where, $\left[\Lambda \mathbf{r}_{\mathrm{k}}\right]$ and $\left[\lambda_{\mathbf{r}_{\mathrm{k}}}\right]$ are diagonal matrices whose diagonal elements are given by $\mathrm{N}_{0} \mathrm{~A}_{0}, \mathrm{~N}_{1} \mathrm{~A}_{1}, \ldots$.. etc. and $\mathrm{N}_{0} \mathrm{~B}_{0}, \mathrm{~N}_{1} \mathrm{~B}_{1}$ ...etc., respectively. Further, the elements of the matrices [Brk] and [D

$$
\begin{aligned}
& B_{00}=\frac{I^{2}}{a} A_{0}+\sum_{m=k}^{\infty} A_{m}^{\prime} M_{m o} M_{m o} ; k=r=0 \\
& B_{0 k}=B_{k 0}=\sum_{m=1}^{\infty} A_{m}^{\prime} M_{m k} M_{m o} ; r=0 ; k \geqslant 1 \\
& B_{r k}=B_{k r}=\sum_{m=1}^{\infty} A_{m}^{\prime} M_{m r} M_{m k} ; r ; k, \geqslant 1
\end{aligned}
$$

and

$$
\begin{aligned}
& D_{00}=\frac{1^{2}}{p} A_{0}+\sum_{f=1}^{\infty} A_{1}^{\prime} M_{10} M_{10} ; k=r=0 \\
& D_{0 k}=D_{k 0}=\sum_{i=1}^{\infty} A_{1}^{\prime} M_{i k} M_{10} ; r=0, k \geqslant 1 \ldots(24) \\
& \left.D_{r k}=D_{k r}=\sum_{i=1}^{\infty} A_{i}^{\prime} M_{i k} M_{i r} ; k, r\right) 1
\end{aligned}
$$




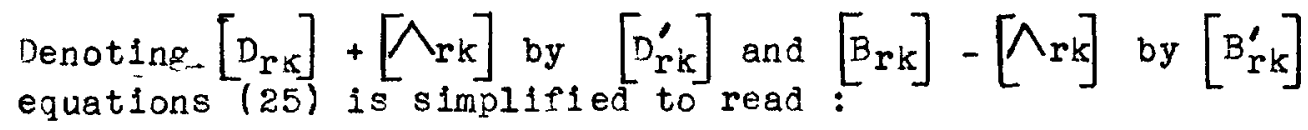

$$
\begin{gathered}
{\left[D_{r k}^{\prime}\right]\left(g_{k}\right)+P_{i_{0}}\left(N_{i_{0} r}=\left[\lambda_{r k}\right]\left(f_{k}\right)\right.} \\
{\left[B_{r k}^{\prime}\right]\left(f_{k}\right)+R_{m o}\left(M_{m_{0} r}\right)=-\left[\lambda_{r k}\right]\left(g_{k}\right)} \\
r=0,1,2, \ldots \infty . \\
k=0,1,2, \ldots \infty .
\end{gathered}
$$

The matrix equation (28) can now be solved for elther $\left(g_{k}\right)$ or $\left(f_{k}\right)$ directly. But, we would like to solve for $f_{k} s$ since the Cscillations inside the port are of immediate interest to us. Further, it may be noted that the ceneral solution should not involve inversion of the diagonal matrix $\left[\lambda_{r k}\right]$ as its elements, for $r, k>\frac{1 K}{\pi}$, tend rapidly to zero as $L$, the length of the Canal, Increases. Eqn, (28) is therefore, reduced as below.

$$
\begin{aligned}
{\left[S_{r k}\right](f k) } & =R_{m o}\left(M_{m o r}\right)-P_{10}\left(E_{r}\right) \ldots \\
r & \Rightarrow k=0,1,2, \ldots \ldots \infty
\end{aligned}
$$

where $\left[\mathrm{S}_{\mathrm{rk}}\right]=\left[\mathrm{G}_{\mathrm{rk}}\right]-\left[\mathrm{B}_{\mathrm{rk}}^{\prime}\right]$

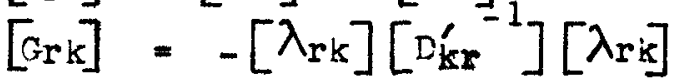

and

$$
\left(E_{\mathrm{r}}\right)=\left[\lambda_{\mathrm{rk}}\right]\left[D_{\mathrm{kr}}^{\prime}{ }^{-1}\right]\left(\mathrm{M}_{\mathcal{I}_{\mathrm{O}}} \mathrm{r}\right)
$$

Solving the matrix equation (29)

$$
\begin{aligned}
& \left(f_{k}\right)=R_{m o}\left[s_{k r}-1\right]\left(N_{m_{0}} r\right)-P_{1_{0}}\left[s_{k r}-\eta\left(E_{r}\right) \ldots(27 a)\right. \\
& \left(\varepsilon_{k}\right)=\left[D_{k}^{\prime}\right]\left[\lambda_{r k}\right]\left(f_{k}\right)-P_{1_{0}}\left[D_{k r}^{\prime}\right]\left(M_{i_{0} r}\right) \ldots(27 b)
\end{aligned}
$$

These operations give $f_{k} s$ and $g_{k} s$ in terms of $R_{m o}$ and $P_{1_{0}}$, the principal "resonant" amplitudes in the report and sea respectively. We note at this stage that to simulate the ocean condition at the domain $D_{s}$, we must take $i_{0}=0$, so that $P_{10}$ is $P_{0}$ and $M_{10}$ is $M_{0}$.

To solve $R_{m o}$ explicitty in terms of $P_{0}$ one must now apply the " resonant "condition $(\varepsilon)$ in the port, viz.

$$
\sum_{k=0}^{\infty} f_{k} M_{\text {mok }}=0 \quad \ldots
$$

Using this value of $R_{m o}$ in equ. (27a) $f_{k} s$ can be obtained in terms of $P_{0}$ and the "resonant" motion everywhere 


\section{COASTAL ENGINEERING}

in the port becomes known interms of the undisturbed amplitude $\left(P_{0}\right)$ of the incident clapotis at the sea outside.

We next investigate the case when the domain $\mathrm{J}_{\mathrm{s}}$ becomes semi-infinite (Fig.2). The previous developments for the port and the canal remain unchanged. Only the potential $\phi_{s}$, for the outer domain, should be established anew and matched at the right end $(y=-L)$ of the communicating canal with the local value of the velocity potential $\phi_{c}$.

A solution for the perturbed potential function in the open sea (domain $D_{S}$ ) can be simply obtained by an extension of a method first outlined by Morse and Rubenstain ( 9 ) for diffraction of electro-magnatic waves by ribbons and slits. The method was later used by Carr and Stelzriede (10) in solving the problem of diffraction of straight crested water waves by a finite gap in a breakwater. Using this method the function $F_{g}(x, y)$ is obtained partly in elliptic-cylindrical co-ordinates $(\phi)$ and partiy rectilinear co-ordinates $(x, y)$; the co-ordinate systems are shown in fle. 3 which is an enlarged view of the right end of the coupling canal.

The varlous co-ordinates shown are related as below -

$$
\begin{aligned}
& x^{\prime}=-x, y^{\prime}=-y+I \\
& x^{\prime}=(d / 2) \cosh \cos \varnothing \\
& y^{\prime}=(d / 2) \sinh \sin \varnothing
\end{aligned}
$$$$
\cdots
$$

For constant $z$, lines of constant $\xi$ and $\varnothing$ become, respectively, confocal ellipses and hyperbola of focal leneth, $d$. When $\varnothing=0$ and $\varnothing=\pi$, the hyperbolas degenerate into a straight line with a gap of width $d$, the gap itself being given by $\xi=0,0<\phi<\pi$, the degenerate ellipse.

We define the function $F_{s}(x, y)$ in the following manner:

$$
\mathrm{F}_{\mathrm{g}}(\mathrm{x}, \mathrm{y})=\boldsymbol{\Psi}(\mathrm{x}, \mathrm{y})+\mathrm{P}_{\mathrm{o}} \operatorname{Cos} \mathrm{K}_{\mathrm{y}} \ldots(30)
$$

In equation (33) the second term on the right satisfies the field equation, eqn ( 2 ), has a zero gradient at the coast line including the gap, and gives when introduced in eqn $(1)$, the potential of principal oscillation mode, $1 . e$. of clapotis, at sea outside. It is, therefore, necessary to find $a \Psi(x, y)$, such that it satisfies equation (2), possess-es a zero gradient at the two coastlines, di sappear at infinty and remain finite in the region of the gap. Me call this function the "perturbation" function and the correspondine potential, the perturbation potential. It is for this function that the elliptic - cylindrical oo-ordinates are useful. 


\section{EFFECT OF ENTRANCE ON SEICHE MOTION IN OCEAN PORTS}

Introducing the co-ordinates of equation (29), the complete solution for the perturbation function $\psi(\xi, \phi)$ that is periodic in $\varnothing$, can be written interms of even an ${ }^{2}$ odd angular and radial Nathieu functions (11)

$$
\begin{gathered}
\boldsymbol{\Psi}(\xi, \phi)=R_{e}\left[\sum_{m=0}^{\infty} \frac{v_{m}}{N m} s_{e m}(s, \phi) J_{e m}(s, \xi)-1 N_{e, m}(s, \xi)\right. \\
\left.+\sum_{m=0}^{\infty} \frac{v_{m}^{\prime}}{N_{m}^{\prime}} s_{o, m}(s, \phi) J_{o m}(s, \xi)-1 N_{o, m}(s, \xi)\right]
\end{gathered}
$$

Where $s=\left(\frac{\pi d}{\lambda}\right)^{2}=\left(\frac{d}{2} \cdot \pi\right)^{2}$

The arbitrary coefficients (to be specialize later) $V_{m}$, and $V_{m}^{\prime}$ may be imaginary and $N_{m}$ and $N_{m}^{\prime}$ are the normalizing factors. This representation of the complex perturbation function gives rise to a perturbation potential individual terms of which represents outward traveling waves that disappear at large distances from the opening. Since only the even function solution satisfy the boundary condition of zero gradient at solld boundarles, we have finally, for the standing waves perturbation function,

$$
\Psi(\xi, \phi)=\operatorname{Re}\left[\sum_{m=0}^{\infty} \frac{V_{m}}{N_{m}} s_{e, m}(s, \phi) J_{e, m}(s, \beta)-1 N_{e, m}(s, \xi)\right]
$$

where $R_{e}$ means the real port.

The coefficients $V_{m}$ are determined by satisfying the boundary condition of equation (6) and we get :

$$
v_{m}=-\frac{21}{N_{e, m}^{\prime}(s, 0)} \sum_{k=0}^{\infty} b_{k} c_{m k} \quad \ldots .
$$

where $i=\sqrt{-1}$ and

$C_{m k}=\frac{d}{2} \int_{0}^{\pi} \cos \frac{k \pi(x-\alpha)}{1} \cdot s_{e, m}(s, \phi) . \sin \phi . d \phi \quad \ldots$.

Introducing equn (33) in (32) and putting the resulting expression for $\Psi(\xi, \varnothing)$ in eqn $(30)$, we get

$F_{\mathbf{g}}(x, y)=P_{0} \cos K_{y}-2 \sum_{k=0}^{\infty} g_{k} \sum_{m=0}^{\infty} \frac{C_{m k}}{N_{m}} \cdot S_{e, m}(s, \phi) \cdot \frac{N_{e, m}(s, \xi)}{N_{e, m}^{\prime}(s, 0)}$ 


\section{COASTAL ENGINEERING}

Equation (39) replaces, then eqn (17) of the finite outer domain case. The right hand side of eqn (22) is similarly replaced by the new serles.

$$
F_{s}(x, L)=P_{0}+2 \sum_{k=0}^{\infty} g_{k} \sum_{m=0}^{\infty} \frac{c_{m k}}{N_{m}} \cdot \frac{f_{e, m}}{\left(\begin{array}{c}
2 \\
g_{e, m}
\end{array}\right)} s_{e, m}(s, \phi) \ldots
$$

Where $\mathrm{f}_{e, m}$ and $\mathrm{ge}_{\mathrm{e}, \mathrm{m}}$ are the joining factors tabulated in Tables relating to Mathieu Functions $\left(11^{*}\right)$. Fur ther developments proceed in a manner similar to that used in the finite domaln case.

The new R.H.S. of eqn (24b) $=\sum_{k=0}^{\infty} g_{k} \sum_{m=0}^{\infty} B_{m} c_{m k} C_{m r}+P_{0} I \delta$ or

$$
\begin{aligned}
& =\sum_{k=0}^{\infty} g_{k} \quad D_{r k}+P_{o l} \delta \text { or } \ldots \\
k, r & =0,1,2 \ldots, \ldots, \infty
\end{aligned}
$$

where,

$$
\begin{aligned}
& B_{m}=\frac{2}{N_{m}} \cdot \frac{f_{e, m}}{g_{e, m}^{2}} \\
& \delta_{\text {or is a Kronecker delta }}=\frac{1}{1} \text { Mor, and } \\
& D_{r k}=\sum_{m=0}^{\infty} B_{m} C_{m k} C_{m r}, k, r=0,1,2, \ldots, \infty
\end{aligned}
$$

The matrix equation (22) is then unchanged except for the fact that we must take $1_{0}=0$ and that the elements of the matrix $\left[D_{r k}\right]$ should be calculated from equation (38) and not from equation (24). Further developments are identical with the steps leading to the equations (25) thru' (28) which gives the desired solution.

For narrow harbour mouths ( $1 \mathrm{~K}<<1$ ), the preceding development for the open sea case reduces to that eiven by Miles and Munk. For instances if we use the entrance velocity distribution function, $\phi_{1}(x)$, proposed by Miles and Munk and adopt their scheme of normalisation for this function then, in the expression for $D(k)$, a term

$$
\left(1^{2} / 2\right) \sum_{m=0}^{\infty}\left(C_{m}^{2} / N_{m}\right)\left(1 / g_{e}, m\right) \exp \left(-1 \tau_{m}\right) \text { is obtained }
$$

instead of the $\operatorname{term}[(-1 / 2) 1+(1 / \pi) \ln (8 / / 1 \mathrm{~K})]$ derived by them. 


\section{EFFECT OF ENTRANCE ON SEICHE MOTION \\ IN OCEAN PORTS}

In these expressions,

$$
\begin{aligned}
\gamma & \left.=1.78 \cdots \dot{f}_{\mathrm{f}, \mathrm{m}}\right), \\
\gamma_{\mathrm{m}} & =-\operatorname{Cot} \text { the Euler's constant, } \\
\text { and } c_{\mathrm{m}} & =\int_{0}^{\pi} \phi_{1}(\mathrm{x}) \cdot \mathrm{s}_{\mathrm{e}, \mathrm{m}}(\mathrm{s}, \emptyset) \text {. Sin } \phi . \mathrm{d} \phi
\end{aligned}
$$

It can now be rearily shown that as $(1 \mathrm{~K})$ tends to $\ll 1$,

$$
\begin{aligned}
\left(1^{2} / 2\right) & \sum_{m=0}^{\infty}\left(C_{m}^{2} / N_{m} \varepsilon_{e, m}\right) \exp \left(-1 \gamma_{m}\right) \rightarrow(1 / \pi) 1_{n}(4.49 / 1 K)-(1 / 2)_{i} \\
& =(1 / \pi) 1_{n}\left(8 / \gamma_{1} K\right)-(1 / 2) i
\end{aligned}
$$

indicating the identity of the two approaches for narrow harbour mouths.

\section{NUTVERICAL EXALPLE}

The dimensions (Refer fig.1) used for the analysis, that are invariant for the various cases studied,are

$$
\begin{aligned}
& a=12, \alpha^{b}=7, \quad p=24, \quad q=24.18 \\
& 1=\beta-\alpha=2
\end{aligned}
$$

The wave period was selected to produce one of the normal modes in each basin, assumed closed. For the port, this was taken to be the case when $m_{0}=n_{0}=1$ and the length of the outer basin was adjusted to make $1_{0}=0$ and $J_{0}=4$, so that the following relationship results :

$$
K_{m_{0} n_{0}}^{2}=\left(\frac{1}{12^{2}}+\frac{1}{\eta^{2}}\right)=K_{1_{0} j_{0}}^{2}=\left(0+\frac{4^{2}}{q^{2}}\right)
$$

from which :

$$
\begin{aligned}
K_{m_{0} n_{0}} & =K_{i_{0} j_{0}}=0.5196 \\
\lambda & =12.09, \text { and } \\
q & =24.18
\end{aligned}
$$

Surface profiles have not been calculated in detail; but the ralues of the function $\mathrm{F}_{\mathrm{p}}(\mathrm{x}, \mathrm{y})$ have been computed at the four corner points viz. $(b, 0),(a, 0),(0, b)$ and $(a, b)$ of the port.

Two effects have been studied. In the first, the length of the communicating canal (I) has been taken as zero, and the entrance location varied as indicated in table I. The same table also shows, for each entrance location, the values of $E_{P}(x, y)$ for $(a)$ a finite sized outer domain $D_{S}$ and (b) a semi-infinite outer domain. 
In the second study only one location of the coupling canal, viz, $\alpha=2, \beta=4$, has been used and the length of the canal $L$ varied to make $L=0, \frac{1}{2}, 1,2,2,1,4$, and $12.09=\lambda$. Table II gives the results of the se computations. The: : results for $L=\lambda$ were obtained by suitably modifyins eqn(16) and prescribing an additional condition, that of "resonance", inside the channel.

The coefficients $A_{m}, A_{1}$ and the integrals $M_{m k}, M_{m r}$ and Mik, Mir have been computed with $m=0-48,1=0-72$ and $r=k=0-4$. For the Open Sea case, the coefficients $B_{m}$ and the integrals $C_{m k}, C_{m r}$ are computed wit $h \quad m=0-6$ and $r=k=0-4$. The convergence of some of the terms were slow and although a formal proof of convergence could not be given, these calculations amply demonstrated that the various series proposed in the analysis do indeed converge absolutely.

\section{EXPLR IMENTS}

The results of the numerical example were verified experimentally in a $7 \mathrm{ft}$. wide concrete channel using the arrangement shown in fig.1. The desired agitation in the finite dimensional sea (GHIJ) was brought in by a narrow communicating channel located at the cent $\operatorname{r}$ of the side IH. Although, this experimental arrangement deviated somewhat from the mathematical model used in the analysis, an involved mathematical formulation of the actual experimental set up showed the difference to be exceedingly small as long as $(1 \cdot K / \pi) \ll 1$.

The water depth and wave length used throughout the experiments were 9 in. and 36.27 in., respectively. The geometrical dimensions of the model were, the refore, threetimes the values, in inches, used in the numerical example. The wave was produced by a simple flap type wave generator driven by a variable speed drive. The wave heights were measured, initially, by means of parallel-wire resistance gauges when the wave generator drive consisted of a variable speed D.C. motor. Later, for better speed control, a constant speed A.C. motor with mechanical speed variation arrangement was installed and it was found thet ordinary point gauges could be used with better accuracy. The results of experimental verification, for one corner of the port, ane presented in figures 4 and 5 .

\section{DISCUSSION OF RLSULTS}

It can be seen, from table 1, that the location of the entrance has a marked effect on the agitation inside the port. But, the difference in the results for the assumption of (a) a finite outer domain, and (b) an open sea is 


\section{EFFECT OF ENTRANCE ON SEICHE MOTION IN OCEAN PORTS}

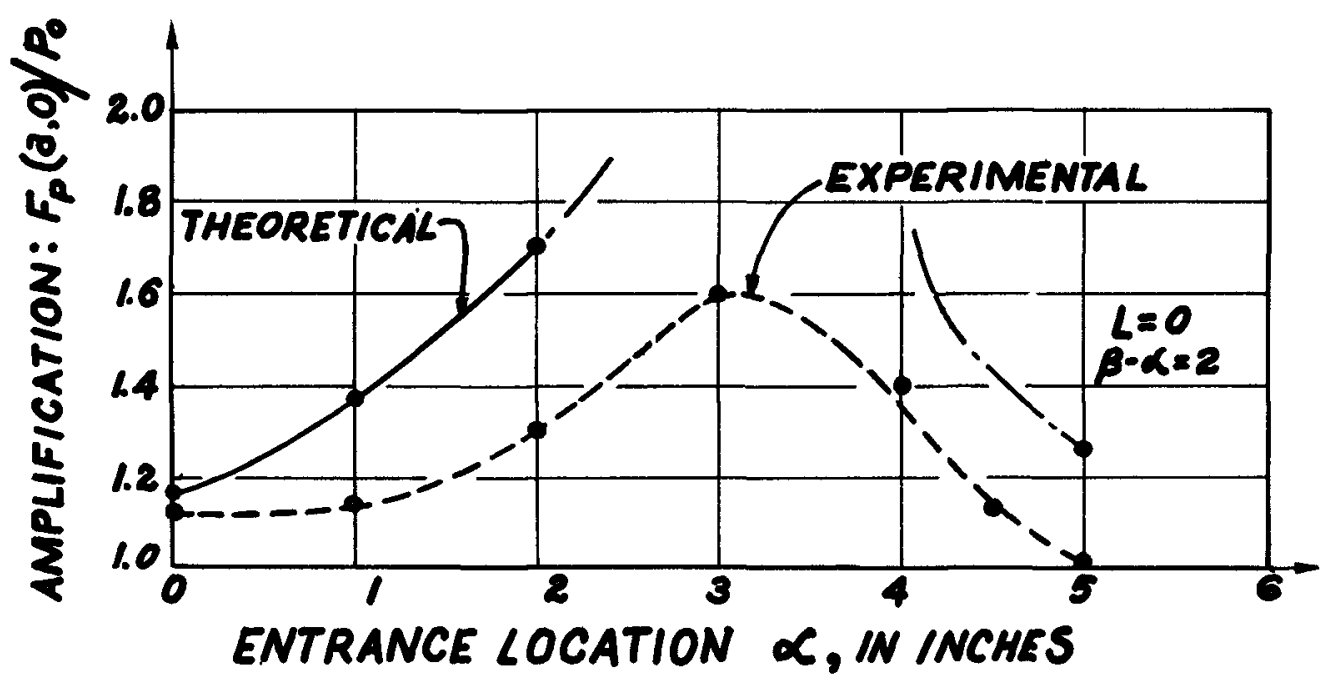

Fig. 4. Comparison of theoretical and experimental amplification factor for corner $(a, 0)$ of harbour.

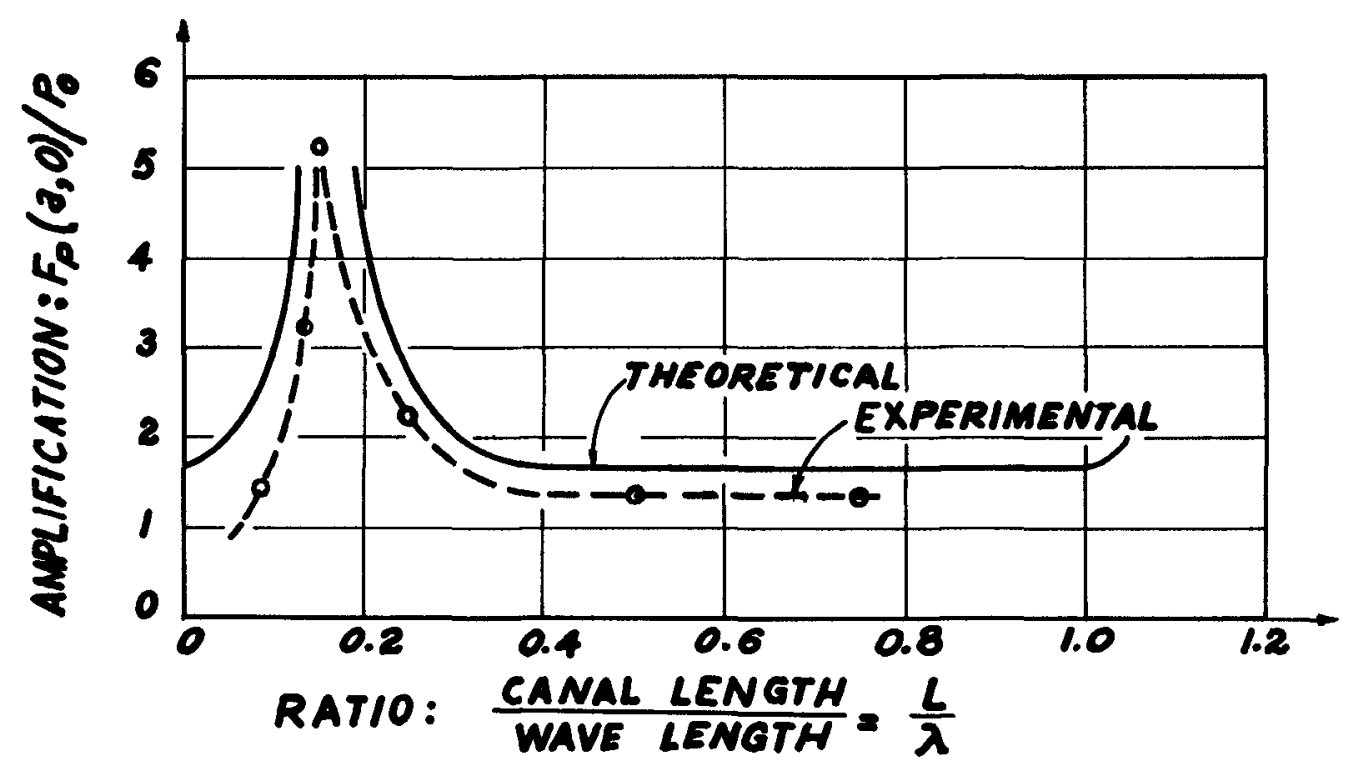

Fig. 5. Comparison of theoretical and experimental amplification factor at corner $(a, 0)$ of harbour for variation in channel length. 


\section{COASTAL ENGINEERING}

negligible even though the finite outer domain is only of moderate size. The quantitative agreement between the experimental and theoretical data presented in fig.4 is rather poor. This is, probably, due to the large hydraulic losses that were associated with the highly adjustable model used in the experiments.

Table II showis that as the length of the coupling canal is increased from zero, the agitation inside the port increases repidiy, attains a peak in the neifhbourhood of $L=2$, and decreases as rapidiy the reafter. When the length of the canal is in the vicinity of the critical length, very large chances in amplitude take place for only slight changes in the canal length. This resulted in somewhat unstable operation in this region. The experiments also falled to realize (see $f 1 g .5$ ) the large amplitude oscillations indicated by the analysis. Simlar disacreement between peaks theoretically predicted and actually observed in the laboratory has been reported by Lellehaute and Raichlen. Although a large part of the observed discrepancy is due to the neglect of alssipative forces in the analysis, breakdown of the linear wave the ory at such large amplitudes of oscillation may be no less important a reason. In fact, for approach channel leneths approaching the critical value, the oscillation modes became remarkably deformed in the regions of high amplitude.

The studies reported here are only exploratory in nature, as caralete response curves have not been determined. The se are in progress. It is possible, even then, to make certain general observations in the light of existing knowledge. For instance, the observod influence of entrance location is due to the presence of a transversal mode of oscillation. Naturaliy, this influence will be less pronounced for osclilations that are primarily longitudinal. Again, a complete response curve wili probably show that the maximum agltation at specified places occur at different frequencies, although the ir magnitudes may only depend on the width of the harbour mouth. It is, therefore meaningless to attempt to segregrate areas in the harbour as 'quiet' or 'alsturbed' zones or specify entrance locations that are particularly desirable unless, the power spectral density of the excitation exterior to the harbour is peaked over only a narrow band width of frequency. The exterior spectrum is, usually, a function of the topographical features of the neighbouring coastline and continental shelf and in some localities the spectrum is indeed peaked at frequencies typical of harbour seiches.

The case with an approach channel interposed between the harbour and the open sea has a special sienificance as, in almost all harbours, the entrance itself has a dimension of length. For a given wave number and harbour geometry, the effect of varying the length of this approach channel is merely to change the phase of the incident wave at the 


\section{EFFECT OF ENTRANCE ON SEICHE MOTION IN OCEAN PORTS}

TABLE - I

(Effect of entrance location on harbour agitation)

\begin{tabular}{|c|c|c|c|c|c|c|c|}
\hline \multirow[t]{2}{*}{ No } & \multicolumn{2}{|c|}{$\begin{array}{l}\text { Lntrance } \\
\text { Location }\end{array}$} & \multirow[t]{2}{*}{$\begin{array}{l}\text { Outer } \\
\text { Sea }\end{array}$} & \multirow[t]{2}{*}{$F_{p}(0,0)$} & \multirow[t]{2}{*}{$F_{p}(a, 0)$} & \multirow{2}{*}{$F_{p}(0, b)$} & \multirow{2}{*}{$F_{p}(a, b)$} \\
\hline & $\alpha$ & $\beta$ & & & & & \\
\hline \multirow[b]{2}{*}{1} & \multirow{2}{*}{0} & \multirow{2}{*}{2} & Finite & 1.03 & -1.16 & -1.15 & 1.26 \\
\hline & & & Open & 1.02 & -1.15 & -1.14 & 1.05 \\
\hline \multirow[b]{2}{*}{2} & \multirow[b]{2}{*}{1} & \multirow[b]{2}{*}{3} & Finite & 1.09 & -1.39 & -1.38 & 1.12 \\
\hline & & & Open & 1.06 & -1.39 & -1.37 & 1.10 \\
\hline \multirow{2}{*}{3} & \multirow{2}{*}{$z$} & \multirow{2}{*}{4} & Finite & 1.12 & -1.68 & -1.64 & 1.17 \\
\hline & & & Open & 1.12 & -1.67 & -1.64 & 1.17 \\
\hline \multirow{2}{*}{4} & \multirow{2}{*}{5} & \multirow{2}{*}{7} & Finite & -.85 & -.85 & -.69 & -.69 \\
\hline & & & $O p \in n$ & -.98 & -.98 & -.80 & -.80 \\
\hline
\end{tabular}

Note : All magnitudes are in terms of $P_{0}$. Length of approach channel, $L=0$.

TABLE - II
(Effect of channel length on harbour agitation)

\begin{tabular}{|c|c|c|c|c|c|c|}
\hline No. & $\begin{array}{c}\text { Outer Sea } \\
\text { \& } \\
\text { Entrance }\end{array}$ & $\begin{array}{l}\text { Aporoach } \\
\text { Channel } \\
\text { Length, I }\end{array}$ & $F_{p}(0,0)$ & $F_{p}(0, b)$ & $F_{p}(a, 2)$ & $F_{P}(a, b)$ \\
\hline 1 & & 0 & 1.12 & -1.68 & -1.64 & -1.17 \\
\hline 2 & Finite & $\frac{1}{3}$ & 1.37 & -1.96 & -1.93 & 1.41 \\
\hline 3 & Outer Sea & 1 & 1.83 & -2.62 & -2.58 & 1.89 \\
\hline 4 & & 2 & 13.35 & -19.14 & -18.84 & 13.80 \\
\hline 5 & $\begin{array}{l}\text { Entrance } \\
\text { Location }\end{array}$ & 2.1 & 40.95 & -58.47 & -57.50 & 42.26 \\
\hline 6 & $\alpha=2$ & 4 & -1.26 & 1.81 & 1.78 & -1.30 \\
\hline 7 & $\beta=4$ & 12.09 & 1.18 & 1.67 & -1.66 & 1.20 \\
\hline
\end{tabular}

Note : All magnitudes are in terms of $P_{0}$. 


\section{COASTAL ENGINEERING}

harbour mouth. In fact, the 'splked' response characteristic: observed in some of the N.I.T. experiments clearly demonstral the need for considering the phase of the incident wave as an additional independent variable in seiche studies. This will be especially important for harbours that project out of the general run of the coast line.

\section{CONCLUSIONS}

As the number of cases studied, numerically as well as experimentally, is small only few definite conclusions can be drawn. The se are :

(1) For the case studied, the proposed open sea solutior is in very good agreement with the solution obtalnec by approximating the open sea by a finite sized. rectangular basin.

(11) The agitation inside a rectangular port is greatly dependent on the entrance location as long as the mode of water motion has primarily transversal oscillation component.

(111) For a given excitation and harbour geometry, there exists a critical length of approach channel which produces maximum agitation inside the harbour basin.

\section{REFERENCES}

1. Knapp, R.T., and Vanoni, V.A. Wave and surge study for the Naval Operating Base, Terminal Island, Calif :

Hydro. Lab. Fub. No.55, Cal1f. Inst. of Tech.,Jan., 1945.

2. Decon, Russel, and Palmer, Origin and effects of long period waves in ports : Communication 1, Section II, XIXth Internatl. Navg. Congress, London, July, 1957 .

3. Wilson, B. Or. Orig and effects of long period waves in ports : Communication 1, Sect.II, XIXth Internatl. Navg. Congress, London, July, 1957.

4. Apte, A.S. Recherches theoriques at experimentales sur les rouvements des liquide peasants avec surface 11 bre. Publ. Scientifiques Et Techniques Du Ministere De L'Air No.338, Faris 1957 .

5. Ippen, A.T. and Rafchlen, F. Tave induced oscillations in harbors : The problem of coupling of highly reflective basins : Hydro. Lab. No.49, Massachusetts Inst. of Tech., May, 1962.

6. Miles, J and Munk, W. Harbor Paradox : Proc. A.S.C.E., Vol.87, No.W 3, pp 111-130, Aug., 1361 . 


\section{EFFECT OF ENTRANCE ON SEICHE MOTION IN OCEAN PORTS}

\section{REFERENCES (CONTD)}

7. Biesel, F. and Le Me'haute', B, Nouvements de resonance a deux dimensions dans une encelnte sous $1^{\prime}$ action

d 'onde incidents : La Houllie Blanche, July - August, 1956.

8. Le Me'haute' B. Theory of wave agitation in a harbor: Proc. A.S.C.E., Volume 87, No.HY2, pp $31-50$, Narch, 1961.

9. Norse, P.W. and Rubehstein, P.J. The diffraction of waves by ribbons and by slits : Thysical Review, Vol.54, Dec., 1938.

10.Carr, J.H. and stelzrlede, N.E. Diffraction of water waves by breakwaters : Gravity Waves, N.B.S. Circular No.521, Nov., 1952.

11. Tables Relating to Mathieu Functions, prepared by the Computation Laboratory, N.B.S., Columbla University Press, 1951. 